\title{
FÓSFORO E ZINCO NO DESENVOLVIMENTO DE MUDAS DE ACEROLEIRA ${ }^{1}$
}

\author{
FERNANDO LUIZ DE OLIVEIRA CORREA ${ }^{2}$, CARLOS ALBERTO SPAGGIARI SOUZA ${ }^{3}$, JANICE GUEDES DE \\ CARVALHO $^{4}$, VANDER MENDONÇA ${ }^{5}$
}

\begin{abstract}
RESUMO- Com o objetivo de verificar o efeito de doses de fósforo e de zinco no desenvolvimento de mudas de aceroleira ( Malpighia glabra L.), conduziu-se um experimento em casa de vegetação situada no pomar do Departamento de Agricultura da Universidade Federal de Lavras-UFLA. As plântulas, após a emergência em canteiros de areia, foram transplantadas em vasos plásticos contendo $1 \mathrm{~kg}$ de solo Latossolo enriquecido com 4 doses de fósforo $\left(0 ; 150 ; 300 \mathrm{e} 450 \mathrm{mg} \mathrm{dm}^{-3} \mathrm{de}\right.$ solo), na forma de superfosfato triplo, e 3 de zinco $\left(0 ; 5 \mathrm{e} 10 \mathrm{mg} \mathrm{dm}^{-3}\right.$ de solo), na forma de sulfato de zinco como substrato. O delineamento experimental utilizado foi o de blocos casualizados, em esquema fatorial 4 x 3 , constituído de 2 plantas por parcela, em 4 repetições. Após 100 dias, avaliaram-se a altura das plantas, o diâmetro do caule, o número de folhas, massa seca da parte aérea (folha e caule) e raízes. As mudas apresentaram incremento linear na altura, diâmetro do caule, número de folhas e na massa seca das raízes e parte aérea. A combinação da dosagem de $450 \mathrm{mg}$ de $\mathrm{P} . \mathrm{dm}^{-3} \mathrm{e} 0 \mathrm{mg}$ de $\mathrm{Zn} \cdot \mathrm{dm}^{-3}$ proporcionou a obtenção de mudas de melhor padrão e com altura superiores às demais.
\end{abstract}

Termos para indexação: acerola, Malpighia glabra L., muda, propagação, nutrição mineral

\section{PHOSPHORUS AND ZINC IN THE GROWTH OF ACEROLA SEEDLINGS}

ABSTRACT- This work was carried out in order to verify the effect of $\mathrm{P}, \mathrm{Zn}$ and their interaction on the growth of acerola (Malpighia glabra L.). The experiment was carried on greenhouse conditions at Lavras Federal University, where seedlings of acerola were planted in pots filled with $1.0 \mathrm{dm}^{3}$ of Latosol. The seedlings were submitted to four rates of $\mathrm{P}\left(0.0,150,300\right.$ and $450 \mathrm{mg} \cdot \mathrm{dm}^{-3}$ of soil $)$ and three rates of $\mathrm{Zn}\left(0.0,5 \mathrm{and} 10 \mathrm{mg} . \mathrm{dm} \mathrm{m}^{-3}\right.$ of soil $)$ obtained from Triple superphosphate and zinc sulphate respectively. After one hundred days the seedlings were harvested and the following parameters were evaluated: plant height, stem girth diameter, dry matter ( root, stem and leaf ) and number of leaves. It was established variance and regression analysis for all parameters indicating a significant effect of $\mathrm{P}$ on all variables and no significant effect of $\mathrm{Zn}$ on the variables. The results showed that the combination of $450 \mathrm{mg}$ of P.dm${ }^{-3}$ and $0 \mathrm{mg}$ of Zn.dm ${ }^{-3}$ of soil provided seedlings better suitable for planting and higher than the others. Index Terms: acerola seedlings Malpighia glabra L., propagation, mineral nutrition

A aceroleira (Malpighia glabra L.), frutífera rústica e arbustiva, é originária das Antilhas, Norte da América do Sul e América Central (Simão, 1971).

Sua cultura vem expandindo-se em regiões tropicais brasileiras, provavelmente devido à demanda elevada e possibilidade de exportações (Andersen e Andersen, 1988; Lucas, 1993). Mesmo sendo a aceroleira uma planta rústica e facilmente adaptável aos mais variados tipos de solo, requer um manejo cuidadoso quanto à adubação e nutrição das plantas, principalmente de pomares para fins de exportação de frutos (Gonzaga Neto e Soares, 1994).

As primeiras pesquisas de nutrição mineral da aceroleira, principalmente referentes à interação entre o fósforo e o zinco, iniciaram-se em 1936. A deficiência de zinco nas plantas, induzida por fósforo, é em função da elevada disponibilidade de fósforo nos solos, decorrentes das adubações. Segundo Olsen (1972), isto ocorre provavelmente devido a: 1) combinação do zinco com o $\mathrm{H}_{2} \mathrm{PO}_{4}$, diminuindo a sua disponibilidade; 2) redução da disponibilidade do zinco por combinação com o cátion acompanhante do fosfato; 3 ) precipitação do fosfato de zinco na superfície das raízes; 4) redução na translocação do zinco das raízes para a parte aérea por causa do alto nível de fosfato nos tecidos condutores; e 5) diminuição no teor de zinco da parte aérea por um efeito diluição, isto é, devido ao maior crescimento por efeito da adubação fosfatada. Outros trabalhos realizados em diversos países relatam a interação fósforo-zinco, sendo que, para cada situação, uma hipótese é apontada como responsável pela explicação da referida interação (Oliveira, 2000)

O fósforo pode aumentar a absorção de zinco pelas plantas, mas a interação só é negativa em condições de alta concentração de fósforo no meio, e baixa concentração de zinco; o mesmo não ocorre quando se aumenta o nível de zinco, pois, com altas doses de fósforo, a planta absorve mais zinco (Wallace, Mueller e Alexander, 1978). Na concentração de $450 \mathrm{mg}$ de P. $\mathrm{dm}^{-3}$ de solo e diferentes doses de zinco, Barbosa (1994) descartou a hipótese de ocorrer interação fósforo-zinco no solo, sugerindo que esta interação parece ocorrer na raiz, diminuindo a translocação e acumulação de zinco, na parte aérea das plantas de aroeira-do-sertão (Myracrodruon urundeuva). Marques (1990), trabalhando com seringueira, também defendeu a mesma hipótese.

Em seringueira, a adubação fosfatada, nas doses de 600 e 1200 $\mathrm{kg}$ de $\mathrm{P}_{2} \mathrm{O}_{5}$. ha ${ }^{-1}$, induziu deficiências acentuadas de zinco, sendo que, nestas doses, a análise foliar das plantas revelou altos teores de $\mathrm{P}$ e baixos de $\mathrm{Zn}$, confirmando a diagnose visual no campo (Pereira et al., 1986). A interação entre o fósforo e o zinco influenciou nas características de crescimento e na nutrição de mudas de maracujazeiro-amarelo e mamoeiro, proporcionando alterações na matéria seca da parte aérea e das raízes ( Machado, 1998 \& Oliveira, 2000)

O presente trabalho teve como objetivo estudar o efeito de diferentes doses de fósforo e de zinco no crescimento de mudas de aceroleira, em condições de casa de vegetação.

O experimento foi realizado em casa de vegetação, localizada no pomar do Departamento de Agricultura da Universidade Federal de Lavras - UFLA, no período de junho a setembro de 1996. O clima da região é temperado suave ( mesotérmico ), tipo Cwb. A região localizase a uma altitude de 913 metros, a uma longitude sul de $21^{\circ} 14^{\prime} 06^{\prime \prime}$ e latitude oeste de $45^{\circ} 00^{\prime} 00^{\prime \prime}$, com temperatura média anual de $19,3^{\circ} \mathrm{C} \mathrm{e}$ umidade relativa do ar de 80\% (Castro netro \& Silveira, 1981).

As sementes, após retiradas dos frutos, foram lavadas e semeadas em canteiros com areia lavada. Posteriormente à emergência, as plântulas foram transplantadas para vasos com capacidade para $1 \mathrm{~kg}$, contendo solo Latossolo coletado na camada de $0-20 \mathrm{~cm}$ no município de Lavras-MG, cuja análise química se encontra na Tabela 1. Após análise do solo, efetuou-se a correção do $\mathrm{pH}$ para $50 \%$ da saturação por bases, conforme descrito por Quaggio (1983), usando-se carbonato de cálcio e de magnésio PA, na relação 4:1. A calagem foi efetuada 20 dias antes da repicagem das mudas.

O delineamento experimental utilizado foi o de blocos casualizados, em esquema fatorial $4 \times 3$, constituído de 2 plantas por parcela, com 4 repetições. Os fatores consistiram das seguintes doses de fósforo $\left(0 ; 150 ; 300 \mathrm{e} 450 \mathrm{mg} \mathrm{dm}^{-3}\right)$, aplicados na forma de superfosfato

1 (Trabalho 191/2001). Recebido: 23/11/2001. Aceito para publicação: 06/09/2002.

2 Eng. Agrônomo, M. Sc. Fitotecnia-Doutorando UFLA /CEPLAC/ESTEX-OP, Ouro Preto do Oeste- RO, C.P. 11

Fone (0xx35)3821-1929 E-mail floc@ufla.br

3 Eng. Agrônomo, Dr. Fitotecnia, CEPLAC / CEPEC, Fone (0xx35)3821-2851 E-mail casouza@ ufla.br

4 Eng. Agrônoma, Dra. Prof ${ }^{\mathrm{a}}$. Titular, Dept ${ }^{\circ}$ de Solos - UFLA, Lavras-MG, CEP 37200-000 Fone (0xx35) 3829-1269 E-mail janicegc@ufla.br

5 Eng. Agrônomo M.Sc. Doutorando-UFLA, Lavras-MG,CEP 37200-000 Fone (0xx35)3822-5210 E-mail vander@ufla.br 
triplo e de zinco $\left(0 ; 5\right.$ e $\left.10 \mathrm{mg}^{-\mathrm{dm}^{-3}}\right)$, na forma de sulfato de zinco, assim distribuídos: $\mathrm{T}_{1}=$ Testemunha; $\mathrm{T}_{2}=0,0 \mathrm{mg}$ de $\mathrm{P} \mathrm{dm}{ }^{-3}+5 \mathrm{mg} \mathrm{de} \mathrm{Zn} \mathrm{dm}{ }^{-3}$; $\mathrm{T}_{3}=0,0 \mathrm{mg} \mathrm{de} \mathrm{P} \mathrm{dm}{ }^{-3}+10 \mathrm{mg} \mathrm{de} \mathrm{Zn} \mathrm{dm}{ }^{-3} ; \mathrm{T}_{4}=150 \mathrm{mg} \mathrm{de} \mathrm{P} \mathrm{dm}^{-3}+0 \mathrm{mg} \mathrm{de}$ $\mathrm{Zn} \mathrm{dm}{ }^{-3} ; \mathrm{T}_{5}=150 \mathrm{mg} \mathrm{de} \mathrm{P} \mathrm{dm}{ }^{-3}+5 \mathrm{mg} \mathrm{de} \mathrm{Zn} \mathrm{dm}^{-3} ; \mathrm{T}_{6}=150 \mathrm{mg} \mathrm{de} \mathrm{P} \mathrm{dm}^{-3}$ $+10 \mathrm{mg} \mathrm{de} \mathrm{Zn} \mathrm{dm}{ }^{-3} ; \mathrm{T}_{7}=300 \mathrm{mg} \mathrm{de} \mathrm{P} \mathrm{dm}{ }^{-3}+0 \mathrm{mg} \mathrm{de} \mathrm{Zn} \mathrm{dm}^{-3} ; \mathrm{T}_{8}=300 \mathrm{mg}$ de $\mathrm{P} \mathrm{dm}{ }^{-3}+5 \mathrm{mg}$ de $\mathrm{Zn} \mathrm{dm}{ }^{-3} ; \mathrm{T}_{9}=300 \mathrm{mg} \mathrm{de} \mathrm{P} \mathrm{dm}{ }^{-3}+10 \mathrm{mg} \mathrm{de} \mathrm{Zn} \mathrm{dm}^{-3}$; $\mathrm{T}_{10}=450 \mathrm{mg} \mathrm{de} \mathrm{P} \mathrm{dm}{ }^{-3}+0 \mathrm{mg} \mathrm{de} \mathrm{Zn} \mathrm{dm}{ }^{-3} ; \mathrm{T}_{11}=450 \mathrm{mg} \mathrm{de} \mathrm{P} \mathrm{dm}^{-3}+5 \mathrm{mg} \mathrm{de}$ $\mathrm{Zn} \mathrm{dm}^{-3} ; \mathrm{T}_{12}=450 \mathrm{mg} \mathrm{de} \mathrm{P} \mathrm{dm}{ }^{-3}+10 \mathrm{mg} \mathrm{de} \mathrm{Zn} \mathrm{dm}^{-3}$. O superfosfato triplo foi finamente moído em grau e misturado ao solo, até completa homogeneização. O sulfato de zinco foi dissolvido na água e aplicado via solução.

Após o transplante das plântulas, efetuou-se uma adubação, baseada na análise de solo, com os seguintes nutrientes: $\mathrm{N}$ (400 mg dm ${ }^{3}$ de solo); K (200 $\mathrm{mg} \mathrm{dm}^{-3}$ de solo); $\mathrm{Mg}$ (36,0 $\mathrm{mg} \mathrm{dm}^{-3}$ de solo); $\mathrm{Cu}$ (1,5 $\mathrm{mg} \mathrm{dm}{ }^{-3}$ de solo); Mo (0,1 $\mathrm{mg} \mathrm{dm}^{-3}$ de solo); e B (0,5 $\mathrm{mg} \mathrm{dm}^{-3}$ de solo). Os nutrientes $\mathrm{N}$ e $\mathrm{K}$ foram aplicados parceladamente em 4 doses, sendo a primeira no plantio das mudas (28-06-96) e as demais aos 30; 45 e 60 dias após o plantio. Como fonte de $\mathrm{N}$, foi utilizado o sulfato de amônio e uréia alternadamente, e como fonte de $\mathrm{K}$ foi usado o cloreto de potássio.

As avaliações referentes aos parâmetros de crescimento foram realizadas mensalmente, durante 3 meses. Na medição do diâmetro do caule, foi utilizado paquímetro metálico, numa altura de $5 \mathrm{~cm}$ do solo. A altura das mudas foi obtida medindo-se cada planta com régua graduada desde o nível do solo até a gema apical. O número de folhas foi obtido através de contagem em cada planta.

Os vasos receberam água desmineralizada de modo a manter a umidade em torno de $60 \%$ do V.T.P. (volume total de poros), sendo o controle efetuado por pesagens diárias dos vasos.

A colheita das plantas foi realizada 100 dias após o plantio das mudas nos vasos e, em seguida, foram colocadas para secar em estufas a $60^{\circ} \mathrm{C}$, até a obtenção do peso constante. Posteriormente, procedeu-se a pesagem da massa seca da raiz, caule e folhas e com moagem do caule e das folhas separadamente para serem submetidos à análise química. Os teores e acúmulos de $\mathrm{P}$ e $\mathrm{Zn}$ na folha e caule são apresentados na Tabela 2.

De maneira geral, o teor e acúmulo de $\mathrm{P}$ e $\mathrm{Zn}$ na folha e caule foram maiores em função das maiores doses destes nutrientes aplicados no solo, sendo o maior teor e quantidade acumulado de $\mathrm{P}$ apresentado na folha com valores de 0,23 e 7,64, respectivamente, ambos na dose de $450 \mathrm{mg} \mathrm{de} \mathrm{P} \mathrm{dm}^{-3}$. Já para o Zn, os maiores valores para teor foi de 70,69 no caule e a maior quantidade acumulada foi de 132,66 no caule obtida com a dose de $10 \mathrm{mg}$ de $\mathrm{Zn} \mathrm{dm}{ }^{-3}$, e $5 \mathrm{mg}$ de $\mathrm{Zn} \mathrm{dm}^{-3}$ respectivamente (Tabela 2).

A característica altura da muda, segundo Ferri (1985), é um parâmetro de grande importância morfofisiológica, pois além de se correlacionar diretamente ao diâmetro, reflete de modo prático o crescimento e a diferenciação do vegetal, favorecendo todo o processo relacionado no sistema solo-planta. Estas duas características foram bastante influenciadas pelas doses de fósforo aplicadas, uma vez que, sem aplicação deste nutriente e seu nível sendo baixo no solo, demonstrado pela análise química (Tabela 1), a altura, principalmente, e o diâmetro foram reduzidos.

Pela análise estatística, verifica-se que as variáveis altura de planta e diâmetro do caule foram influenciadas somente pelas aplicações de fósforo, observando-se uma resposta linear positiva (Figura 1). Em seringueira, Marques (1990) também observou que a altura de portaenxerto apresentou crescimento linear positivo em relação às doses de fósforo. Respostas também positivas da adição de fósforo sobre o crescimento e diâmetro de diferentes frutíferas foram relatadas por diferentes autores: Lira (1990), com mudas de citros, Oliveira (1986) e Rocha (1987), com mudas de mamoeiro.

Em relação ao diâmetro do caule, os resultados encontrados assemelham-se aos de Peixoto (1986) que, estudando o efeito da matéria orgânica, do superfosfato simples e o cloreto de potássio na formação de mudas de maracujazeiro, detectou aumento do diâmetro do caule em função dos incrementos nas doses de $\mathrm{P}$ em relação à ausência do mes- mo.

Na característica número de folhas, observou-se, pela análise de variância, que tanto as doses de fósforo quanto a interação fósforo zinco apresentaram significância. Na interação, os melhores resultados para esta característica foram obtidos sem aplicação de Zn e $450 \mathrm{mg}$ de $\mathrm{P} \mathrm{dm}^{-3}$ de solo ou com a aplicação de $5 \mathrm{mg} \mathrm{de} \mathrm{Zn} \mathrm{dm}^{-3} \mathrm{e} 300 \mathrm{mg} \mathrm{de} \mathrm{P} \mathrm{dm}$ ${ }^{3}$, com a aceroleira apresentando número médio de folhas de 70 e 71, respectivamente. Já o menor número de folhas foi encontrado na dose de $5 \mathrm{mg} \mathrm{de} \mathrm{Zn} \mathrm{dm}^{-3}$ e $0 \mathrm{mg} \mathrm{de} \mathrm{P} \mathrm{dm}^{-3}$ (Figura 2). Em mudas de maracujazeiro-amarelo, Machado (1998) encontrou respostas diferentes para esta característica, porém deve levar-se em consideração que são espécies diferentes. Estas respostas positivas para a aplicação de $\mathrm{P}$ para todas as características de crescimento e desenvolvimento do vegetal refletem nitidamente um dos seus principais papéis, notadamente na formação das raízes (Malavolta, Vitti e Oliveira, 1997)

As equações de regressão para a massa seca das folhas e do caule são mostradas na Figura 3, na qual o comportamento do fósforo apresenta significância. Os maiores acréscimos de produção de massa seca, tanto das folhas como do caule, foram observados na dose de 450 $\mathrm{mg}$ de $\mathrm{P} \mathrm{dm}^{-3}$. Tais dados indicam que, em futuros trabalhos, envolvendo a produção de mudas de aceroleira empregando o fósforo, maiores doses deste nutriente devem ser estudadas, uma vez que, até a dose de $450 \mathrm{mg} \mathrm{dm}^{-3}$, a resposta foi linear.

Assim como observado para altura e diâmetro, os aumentos na produção de massa seca das folhas e caule foram altamente dependentes do fósforo, não apresentando respostas à aplicação do zinco. Isto demonstra a importância do fósforo para o crescimento das mudas de aceroleiras, o qual participa da formação da parede celular e vários processos metabólicos, que são vitais ao desenvolvimento da planta (Marschines, 1997).

TABELA 1 - Resultado da análise química do solo da camada de 0-20 cm utilizado no experimento com aceroleira em Lavras-MG, realizado pelo Laboratório de Fertilidade do Solo da UFLA- Lavras-MG, 1996

\begin{tabular}{|c|c|c|c|c|c|c|c|c|c|c|c|c|c|c|c|c|}
\hline $\mathrm{pH}$ & $P$ & K & $\mathrm{Ca}$ & $\mathrm{Mg}$ & Al & $\mathrm{H}+\mathrm{Al}$ & SB & $t$ & $\mathrm{~T}$ & & V & C & M.0. & $S$ & B & $\mathrm{Zn}$ \\
\hline $\mathrm{H}_{2} \mathrm{O}$ & $\mathrm{mg}$ & $\mathrm{dm}^{3}$ & \multicolumn{7}{|c|}{$\mathrm{cmol} / \mathrm{dm}^{3}$} & \multicolumn{3}{|c|}{$\%$} & $\mathrm{dag} / \mathrm{kg}$ & \multicolumn{3}{|c|}{$\mathrm{mg} / \mathrm{dm}^{3}$} \\
\hline 5,0 & 2,0 & 16 & 8,0 & 4,0 & 1,0 & 23 & 12 & 13 & 35 & 7 & 35 & 0,7 & 1,2 & 6,38 & 0,08 & 0,8 \\
\hline
\end{tabular}

TABELA 2 - Teor e acúmulo de fósforo e zinco na matéria seca de folha e caule de mudas de aceroleira adubadas com fósforo e zinco. UFLA- Lavras-MG, 1996.

\begin{tabular}{|c|c|c|c|c|c|c|c|c|}
\hline & \multicolumn{4}{|c|}{ Teor } & \multicolumn{4}{|c|}{ Acúmulo } \\
\hline & \multicolumn{2}{|c|}{ Fósforo (g/kg) } & \multicolumn{2}{|c|}{ Zinco $(\mathrm{mg} / \mathrm{kg})$} & \multicolumn{2}{|c|}{ Fósforo (mg/planta) } & \multicolumn{2}{|c|}{ Zinco ( g/planta) } \\
\hline & $\begin{array}{c}\text { Matéria } \\
\text { seca da } \\
\text { Folha }\end{array}$ & $\begin{array}{c}\text { Matéria } \\
\text { seca do } \\
\text { Caule }\end{array}$ & $\begin{array}{c}\text { Matéria } \\
\text { seca da } \\
\text { Folha }\end{array}$ & $\begin{array}{c}\text { Matéria } \\
\text { seca do } \\
\text { Caule }\end{array}$ & \begin{tabular}{|c|} 
Matéria \\
seca da \\
Folha \\
\end{tabular} & $\begin{array}{c}\text { Matéria } \\
\text { seca do } \\
\text { Caule }\end{array}$ & $\begin{array}{c}\text { Matéria } \\
\text { seca da } \\
\text { Folha }\end{array}$ & $\begin{array}{c}\text { Matéria } \\
\text { seca do } \\
\text { Caule }\end{array}$ \\
\hline $\mathrm{T}_{1}$ & 0,09 & 0,08 & 35,57 & 24,64 & 0,41 & 0,24 & 15,65 & 9,80 \\
\hline $\mathrm{T}_{2}$ & 0,12 & 0,08 & 52,95 & 52,01 & 0,63 & 0,41 & 28,82 & 26,42 \\
\hline $\mathrm{T}_{3}$ & 0,11 & 0,10 & 41,37 & 52,15 & 1,46 & 1,96 & 50,09 & 77,43 \\
\hline $\mathrm{T}_{4}$ & 0,15 & 0,11 & 40,78 & 39,78 & 2,35 & 1,35 & 54,71 & 45,45 \\
\hline $\mathrm{T}_{5}$ & 0,18 & 0,15 & 31,20 & 49,50 & 3,16 & 1,35 & 54,84 & 77,30 \\
\hline $\mathrm{T}_{6}$ & 0,17 & 0,13 & 39,06 & 48,83 & 3,41 & 2,22 & 79,58 & 91,68 \\
\hline $\mathrm{T}_{7}$ & 0,18 & 0,12 & 27,86 & 37,20 & 2,65 & 1,48 & 43,29 & 47,28 \\
\hline $\mathrm{T}_{8}$ & 0,18 & 0,16 & 31,3 & 53,06 & 5,96 & 4,76 & 102,40 & 157,03 \\
\hline $\mathrm{T}_{9}$ & 0,18 & 0,14 & 34,38 & 70,69 & 2,70 & 1,67 & 63,76 & 108,08 \\
\hline$T_{10}$ & 0,23 & 0,21 & 27,66 & 30,63 & 7,64 & 6,43 & 95,07 & 98,54 \\
\hline $\mathrm{T}_{11}$ & 0,19 & 0,14 & 37,85 & 55,78 & 5,93 & 3,37 & 113,05 & 132,66 \\
\hline $\mathrm{T}_{12}$ & 0,22 & 0,14 & 40,08 & 57,96 & 4,77 & 2,85 & 84,57 & 108,83 \\
\hline
\end{tabular}

Diferentemente da acumulação de massa seca no caule e folhas, onde só houve respostas significativas para as doses de fósforo, a massa seca das raízes, além de apresentar respostas significativas para as doses de fósforo, também apresentou interação significativa para as aplicações de fósforo e zinco (Figura 4). Observou-se que, sem a aplicação de $\mathrm{P}$ e Zn, se obteve o menor valor para a massa seca, e com a dose de $300 \mathrm{mg} \mathrm{de} \mathrm{P} \mathrm{dm}^{-3}$ e $5 \mathrm{mg} \mathrm{de} \mathrm{Zn} \mathrm{dm}{ }^{-3}$ houve a maior produção de raízes. 
Estas respostas assemelham-se às encontradas por Machado (1998), que também encontrou interação significativa tanto para $\mathrm{P}$ como para a interação $\mathrm{P}$ e $\mathrm{Zn}$ na matéria seca das raízes de mudas de maracujazeiroamarelo e as encontradas por Oliveira (2000) em mudas de mamoeiro. Além disso, confirmam a quarta hipótese de Olsen (1972) e a proposta de Barbosa (1994), que relata a interação fósforo-zinco no solo em plantas de aroeira-do-sertão e sugere que esta interação ocorreria nas raízes, diminuindo a traslocação de zinco na parte aérea.

Com base nos resultados desta pesquisa, conclui-se que:

As mudas apresentaram incremento linear para as características altura, diâmetro do caule, número de folhas e na massa seca das raízes e da parte aérea em função das doses de fósforo aplicadas.

A adição de fósforo na dose de $450 \mathrm{mg} \mathrm{de} \mathrm{P} \mathrm{dm}^{-3}$ pode melhorar o desenvolvimento das mudas de aceroleiras.

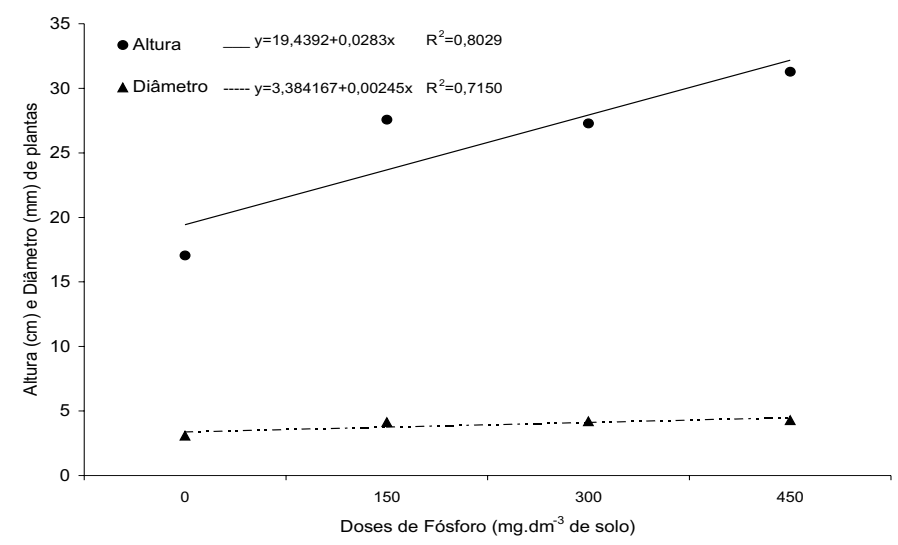

FIGURA 1 - Efeito da aplicação de P sobre a altura e diâmetro de mudas de aceroleira. UFLA - Lavras-MG, 1996

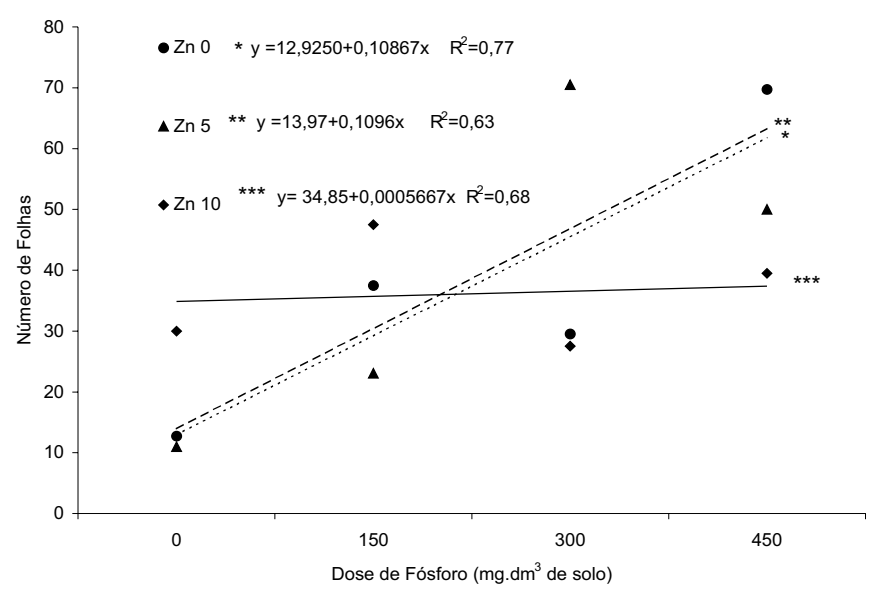

FIGURA 2 - Efeito da aplicação de P e Zn sobre o número de folhas de mudas de aceroleira. UFLA Lavras-MG, 1996.

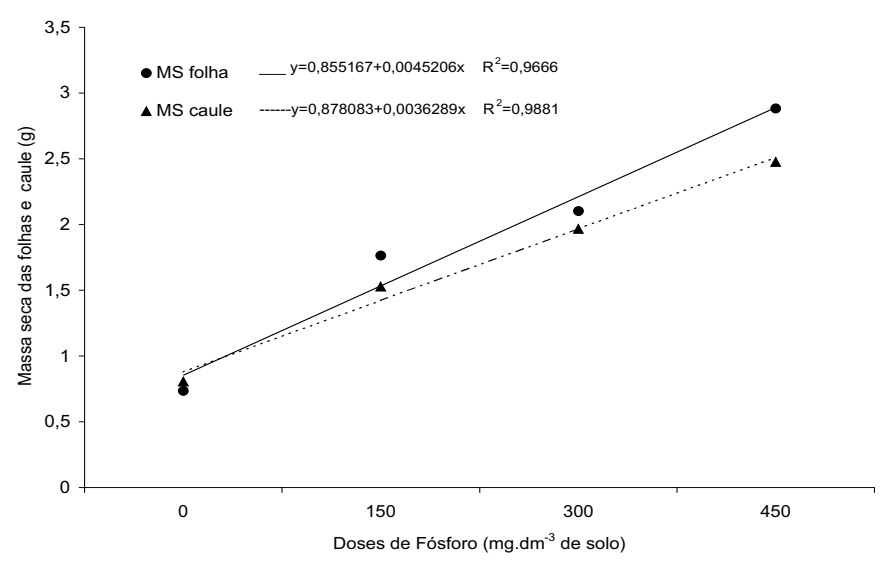

FIGURA 3 - Efeito da aplicação de P na massa seca das folhas e do caule em mudas de aceroleira. UFLA Lavras-MG, 1996.

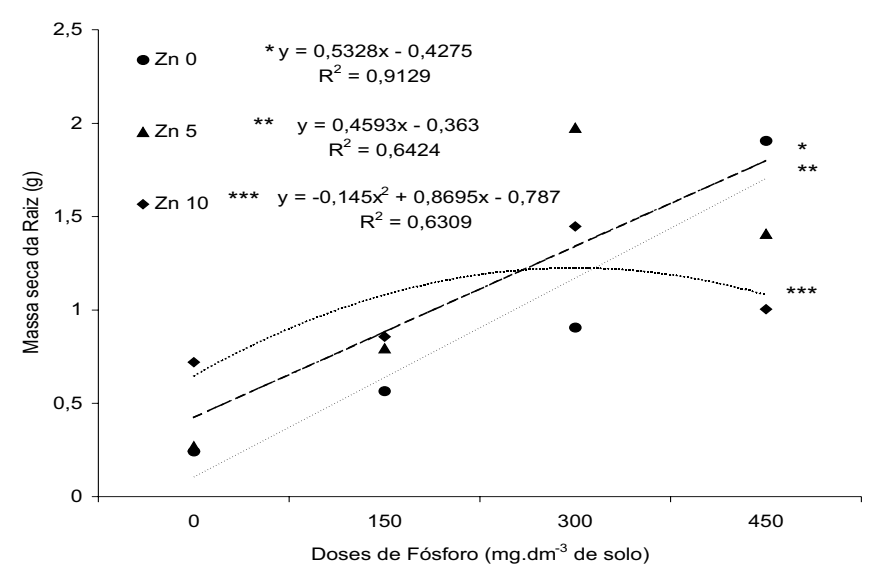

FIGURA 4 - Efeito da aplicação de P e Zn na massa seca da raiz em mudas de aceroleira. UFLA Lavras-MG, 1996.

\section{REFERÊNCIASBIBLIOGRÁFICAS}

ALVES, R.N.B. Níveis de Nitrogênio, fósforo, potássio e magnésio para produção de porta-enxertos de seringueira (Hevea spp) no Amapá. 1987. 79f. (Mestrado em Solos e Nutrição de Plantas) - Escola Superior de Agricultura de Lavras, Lavras, 1987.

ANDERSEN; ANDERSEN, V.V. As frutas silvestres brasileiras. Rio de Janeiro: Globo, 1988. 203p.

BARBOSA, Z. Efeito do fósforo e do zinco na nutrição e crescimento de Myracrodruon urundeuva Fr. All. (Aroeira-do-Sertão). 1994.105f. ( Mestrado em Solos e Nutrição de Plantas) - Universidade Federal de Lavras, Lavras, 1994

CASTRO NETO, P.; SILVEIRA, S.V. Precipitação provável para Lavras, Região Sul de Minas Gerais, baseada na função de distribuição de probabilidade gama. 1 Período mensais. Ciência e Prática, Lavras, v.5, n.2, p.144-151, 1981.

DE GEUS, J. G. Fertilizer requirements of tropical fruit crops. Stikstof, The Hague, v.8, p.41-64, 1964.

FERRI, M.G. Fisiologia vegetal. São Paulo:EPU, 1985.362p.

GONZAGA NETO, L.; SOARES. J.M. Acerola para exportação: aspectos técnicos da produção. Brasília: Embrapa-SPI/FRUPEX, 1994.43p. (Série Publicações Técnicas, 10).

LIRA, L. M. Efeito de substratos e do superfosfato simples no limoeiro (Citrus limonia Osbeck. cv..“Cravo”) até a repicagem. 1990. 86f. Tese (Mestrado em Fitotecnia) - Escola Superior de Agricultura de Lavras, Lavras, 1990

LUCAS, A. P. Acerola: suco da saúde conquista o mundo inteiro. Manchete Rural, Rio de Janeiro, v.5, n.69, p.10-13, 1993.

MACHADO, R.A.F. Fósforo e zinco na nutrição e crescimento de mudas de maracujazeiro amarelo (Passiflora edulis f. flavicarpa Deg.). 1998. 93f. Dissertação (Mestrado em Fitotecnia) - Universidade Federal de Lavras, Lavras, 1998

MALAVOLTA, E. Elementos de nutrição mineral de plantas. São Paulo: Ceres, 1980.251p.

MALAVOLTA, E.; VITTI, G.C.; OLIVEIRA, S.A de. Avaliação do estado nutricional das plantas. 2. ed. rev. atual. Piracicaba: POTAFOS, 1997. 319p.

MARQUES, R. Efeitos do fósforo e zinco na nutrição e crescimento de porta-enxertos de seringueiras (Hevea brasiliensis Muell. Arg.) 1990. 110f. (Mestrado em Solos e Nutrição de Plantas) - Escola Superior de Agricultura de Lavras, Lavras, 1990

MARSCHNER, H. Mineral Nutrition of higher plants. 2. ed. San Diego: Academic Press, 1997. 889p.

OLSEN, S.R. Micronutrient Interaction. In: MORTVEDT, J.J.; GIORDANO, P.M.; LINDSAY, W.L. (Ed.) Micronutrients in Agriculture. Madison: Soil Science Society of America, 1972. p.243-264.

OLIVEIRA, P.R.A. Efeito do fósforo e zinco na nutrição e crescimento de mudas de mamoeiro e mangabeira 2000. 184f. Tese (Doutorado 
em Fitotecnia) - Universidade Federal de Lavras, Lavras, 2000.

OLIVEIRA, P.R.A. Efeito do superfosfato simples e do calcário dolomítico na formação de mudas de mamoeiro (Carica papaya L. cv. Solo). 1986. 110f. Dissertação (Mestrado em Fitotecnia) - Escola Superior de Agricultura de Lavras, Lavras, 1986.

PEIXOTO, J.R. Efeito da matéria orgânica, superfosfato simples e do cloreto de potássio na formação de mudas de maracujazeiro-amarelo (Passiflora edulis Sims). 1986. 101f. Dissertação (Mestrado em Fitotecnia) - Escola Superior de Agricultura de Lavras, Lavras, 1986.

QUAGGIO, J.A. Critérios para calagem em solos do Estado e São Paulo. 1983. 86f. Dissertação - (Mestrado em Solos e Nutrição de Plantas) - Escola Superior de Agricultura “Luiz de Queiroz”, Universida- de de São Paulo, Piracicaba, 1983

ROCHA, A.C. da. Efeito da matéria orgânica e do super fosfato simples na formação de mudas de mamoeiro ( Carica papaya L. cv. Solo). 1987.52f. Dissertação (Mestrado em Fitotecnia) - Escola Superior de Agricultura de Lavras, Lavras, 1987

SIMÃO, S. Manual de fruticultura. São Paulo: Ceres, 1971.530p.

TAIZ, L.; ZEIGER, E. Plant Physiology. California: The Benjamin Cummings Company, 1991.565p.

WALLACE, A.; MUELLER, R.T.; ALEXANDER, G.V. Influence of phosphorus on zinc, iron, manganese and copper uptake by plnts. Soil Science, Baltimore, v.126, n.6, p.336-341, 1978. 